\title{
Road Traffic Accident Scenario, Pattern and Forecasting in Bangladesh
}

\author{
Md Shakhawat Hossain*, Md Omor Faruque \\ Department of Statistics, University of Chittagong, Chittagong, Bangladesh \\ Email: *shakhawat.stat@cu.ac.bd
}

How to cite this paper: Hossain, Md.S. and Faruque, Md.O. (2019) Road Traffic Accident Scenario, Pattern and Forecasting in Bangladesh. Journal of Data Analysis and Information Processing, 7, 29-45. https://doi.org/10.4236/jdaip.2019.72003

Received: January 2, 2019

Accepted: March 2, 2019

Published: March 5, 2019

Copyright (c) 2019 by author(s) and Scientific Research Publishing Inc. This work is licensed under the Creative Commons Attribution International License (CC BY 4.0).

http://creativecommons.org/licenses/by/4.0/

\section{cc) (7) Open Access}

\begin{abstract}
The main aim of this research work is to be aware of the road traffic accident scenario, injurious effects and pattern in Bangladesh. Moreover we are interested to forecast the magnitude of road traffic accidents for the future so that decision makers can make appropriate decision for precaution. This study also provides an assessment of road traffic accidents in Bangladesh and its impact based on data collected for the period of 1971 to 2017. In this study we have tried to pick up the main reasons of road accidents and to observe the tremendous situation. The study observed that the general trends of road traffic accident (RTA), deaths and injuries reveal that the number of RTA, deaths and injuries increased gradually with little fluctuations form 1971 to 2007 and after 2007 there is a slow decreasing trend. Although the number of RTA and deaths observed decreasing trend in recent years, the ratio of number of deaths to number of accident increased significantly. The rate of register vehicles per 10,000 people increased moderately throughout the period but a sharp increment is exhibited from 2009. Highest percentage of RTA (34\%) and deaths is due to RTA (32\%) in Dhaka division while the lowest percentage of RTA (4\%) in Barisal and Sylhet divisions and deaths is due to RTA (3\%) in Barisal division. It is noticed that the maximum number of injuries occurred between ages 21 and 30 while the maximum number of deaths occurred between ages 11 and 30. Most of the RTA and deaths due to RTA are caused by run over by vehicles and head to head collision. The severity of occurring road accident and number of deaths are higher during the festive periods because of involving higher frequency of traveling than usual. The time plot shows that the graph maintains a decreasing movement from 2012 to 2015 but increases from 2015 to 2017. In the research an additive time series model approach is applied. It included the estimation of trend, seasonal variation and random variation using triple exponential smoothing method. We performed forecasting of RTA eliminating seasonal impact for the next three consecutive years (2018-2020) with 95\% confidence interval using
\end{abstract}


Holt-Winters exponential technique.

\section{Keywords}

Road Accident, Trend, Seasonal Variation, Exponential Smoothing, Forecasting

\section{Introduction}

Road traffic accident (RTA) has become one of the major concerns for the development of a country. A developing country like Bangladesh is not apart from its effects. In spite of great progress in international traffic safety works, traffic accidents are still the cause of large and increasing number of fatalities and severe injuries particularly in developing countries like Bangladesh. Road traffic accident occurs when a vehicle is moving along a roadway collides with another vehicle or object. Traffic collisions often result in injury, property damage and even death. Road traffic accident in Bangladesh has been identified as one of the major causes of deaths in the country. In recent year road traffic accident was classified as the eight major cause of death or disability out of a total of over 50 separately identified causes. However, by the year 2030 forecasts suggest that as a cause of death, road traffic accidents will move up to fifth place [1]. In case of Bangladesh, the number of accidents and fatalities on the road is also stepping up with the passage of time.

According to the record of police (2015), in last 21 years 84,000 road accidents occurred, 56,000 died and 63,000 injured [2]. But the actual number is higher than the aforementioned figure because all the people who suffer injury don't make a general diary at the police station. Similarly it is not possible for the police to keep records of all road accidents. Thus different government or non-government organizations are trying to find an actual number of road accidents with its causalities. A report published in Prothom Alo sources from BRTA [3], reported that there were an accident statistics which suggested that the damages due to RTA were worth 40 thousands crore taka in the last 3 years [4]. It also showed that Bangladesh is losing 2\% - 3\% gross domestic product (GDP) in each year for the causal impact of road accidents.

Official results and information from other sources may not match with the police record databases. For example, in the Philippines, only one out of five medically reported road deaths are included in police statistics. In Indonesia, insurance companies report almost 40 percent more deaths than the police [5]. With the increase in population, the rate of road accidents is increasing day by day. In 2017 there were 3349 road accidents with 5645 fatalities and 7908 injuries in Bangladesh [6]. This reveals that there was an average of 9 deaths every day in Bangladesh in the past year which was caused by road accidents. The most dangerous part of it all is that most of the people who are died by road accidents are those in the age group that constitute the work force of this nation. In this re- 
gard, more attention needs to be placed on the research into road accident and its impact on human lives and properties in Bangladesh.

Transport is an essential part of any economy and Bangladesh is not beyond it. But unfortunately, the authority can't pay proper attention to traffic and transportation due to the higher growth rate of the population as well as increasing transport problems. Traffic roads are expanded dynamically without any planning and control due to the rapid socioeconomic changes and to fulfill the demand of growing population.

Vehicular accident in this country has become one of the growing concerns to most Bangladeshis in recent times. As a result of the tremendous effect of accidents on human lives, properties and the environment are vulnerable. Many researchers have come out with the causes, effects and recommendations to vehicular accidents. In Bangladesh, most of the relevant studies focused on aggregate accident information and thereby assist in assessing the extent and nature of road accidents. Only few studies have been done considering detail spectrum of factors of road accidents for a comprehensive understanding of the characteristics of accident problems.

This research seeks to achieve the following objectives:

1) To see the RTA scenario, patterns and its frequency.

2) To locate most accident porn locations.

3) To examine the seasonal variation of RTA.

4) To forecast the number of RTA for the future.

Followed by the introduction the article is organized as literature review, data and methodology, results and discussion. Finally conclusion and recommendations is presented.

\section{Literature Review}

Ahsan et al. [7] showed the car accident scenario in Bangladesh during the period 1998-2009. About 7 percent of these accidents and 3 percent of the people died involved cars. Car accidents occur mainly on highways and streets and significant causes are speeding (46.5\%) and careless driving (48.8\%). Major collision types are rear end (33.3\%), hit pedestrians (25.8\%) and head on (17.4\%). Accident occurrences merely varied during day and night time. Sonia [8] developed a prediction model of accident which found the approximate number of accidents that can happen per year and thus they recommended taking proper steps and precautions such as speed breakers, road dividers, proper signs, marking, speed limit, proper signal design to avoid such accidents.

Ahmed and Ahmed [9] focused on few parameters: trend in overall accident rates, monthly variation of accident rates, accidents by severity levels, collision types and accidents in different lighting conditions in their study conducted in Dhaka city for the period 2007-2011. They observed that on an average the total number of traffic accidents is reduced by $11 \%$ while number of fatality is increased. They also concluded that fatal accidents and motor collisions are de- 
creasing while injury accidents are increasing. Most traffic accidents: cause fatality (69\%) and hit a pedestrian (60\%). Mamun et al. [10] conducted a study on the data of accidents for three years (2011-2013) of Rajshahi city in Bangladesh. It has been found that six intersections and four mid-blocks are the most hazardous, where the rate of accident frequency is high. The analysis also showed that $41.67 \%$ victims were between ages 20 to 35 years old. The vehicles are mostly responsible for accidents that are trucks (26\%) and buses (23\%). Truck accidents caused in city road accidents contribute $32.56 \%$ of total deaths and Bus $23.26 \%$.

Baset et al. [11] conducted a study which was described the current magnitude and risk factors of road traffic injury (RTI) for different age groups in rural Bangladesh. They found that the RTI mortality and morbidity rates were significantly higher among males compared to females. Deaths and morbidities due to RTI were highest among those in the 25 - 64 years age group. A higher proportion of morbidity occurred among vehicle passengers (34\%) and pedestrians (18\%), and more than one-third of the RTI mortality occurred among pedestrians. Ferdus et al. [12] showed that Natore-Rajshahi-Nawabganj highway (N6) is the most hazardous road in Rajshahi city and head on collision is the leading reason for accident in this road. The rate of death is also very high on city roads. About $46 \%$ of the total victims were between ages 21 to 30 years old. In more than one third of the total analyzed accidents pedestrians are the victims including deaths and fatalities. About $50 \%$ of the total casualties occurred, either motorcycle or truck are involved.

Nofel and Sayeed [13] carried out a study to make a decision about the Seasonal variation and weather effects on road traffic accidents in Riyadh City. In their study they showed that total RTA accidents were significantly more common, being directly correlated with increased dry and wet conditions and significantly less common, being inversely correlated with increased relative humidity and amount of precipitation of rain, snow, hail etc. However, seasonal variation in RTAs was evident being maximal during the summer season particularly between 12 noon and $3 \mathrm{pm}$. This period is characterized by heavy traffic and intense sunlight. Favour et al. [14] aimed to find a suitable time series model to forecast the future characteristics of the road accident data on Oyo-Ibadan express road in Nigeria. The data used for the study was monthly data collected for a period of eleven years between 2004 and 2014. In achieving this, the additive model approach was adopted in the analysis. It included the estimation of trend, seasonal variation and random variation using moving average method. Autoregressive Moving average model were also fitted to the data.

So far our knowledge the extensive research works about road traffic accident in Bangladesh has not been carried out.

\section{Data and Methodology}

This study deals with a detailed description of the methods used for this research 
and explained the theory behind the analysis. The chapter addressed the seasonal variation of no of accident from 2012 to 2017 and forecast thereby. It also provided the description of the software packages used for the analysis and modeling.

\subsection{Source of the Data}

We have collected secondary data (yearly) regarding road traffic accident from Accident Research Institute (ARI) for the period 1971 to 2015. ARI constructs its database on the basis of filled Accident Reporting Forms (ARF) preserve in various police stations through the Bangladesh Police Department. Besides this we have collected more detailed, comprehensive and very recent monthly data about road traffic accident from Bangladesh Road Transport Authority (BRTA) and a non-government organization Nirapad Sharak Chi (NISHCA) [4] for last six years 2012 to 2017. All these collected data are time series data.

\subsection{Methodology}

Different descriptive statistical tools and graphical presentations are applied to see the actual scenario of road accident in Bangladesh. Trend components and seasonal indices are estimated. Augmented Dickey-Fuller (ADF) test (a unit root test) and Philip Perron test are used to examine if the data is stationary or not. The usual practice is to include a number of lags sufficient to remove serial correlation in the residuals. We have fitted smoothing forecasting model for the data. Smoothing techniques are used to reduce irregularities in time series data. They provide a clear view of the true underlying behavior of the series. Smoothing can remove seasonality and makes long term fluctuations in the series stand out more clearly.

\subsubsection{Seasonal Variation and Forecasting}

The best way to start with any time series forecasting analysis is to graph sequence plots of the time series to be forecasted. The purpose of the sequence plot is to give a visual impression of the nature of the time series. This visual impression would suggest if there are certain behavioral "components" present within the time series. The presence or absence of such components can help the analyst in selecting the model with the potential to produce the best forecasts.

Exponential smoothing, a method of time series forecasting, is a procedure of continuous revising a forecast in the light of more recent experience. Exponential smoothing assigns exponentially decreasing weights as the observation get older. In other words, recent observations are given relatively more weight in forecasting than the older observations. This study concentrates on the Holt-Winters [15] exponential smoothing technique as applied to time series that exhibits trend and seasonality. Holt-winters method also best suits for short term forecasting.

Often, time series data display behavior that is seasonal. Seasonality is defined 
to be the tendency of time-series data to exhibit behavior that repeats itself every Lag period. The term season is used to represent the period of time before behavior begins to repeat itself. $\mathrm{L}$ is therefore the season length in periods. When the seasonal effect at any period differ slowly from year to year, in this case, the seasonality is additive and from this point of view we prefer additive model for the seasonality in road accident data.

Consider an Additive Seasonal Model as

$$
y_{t}=b_{1}+b_{2} t+S_{t}+\varepsilon_{t}
$$

where $b_{1}$ is the base signal also called the permanent component, $b_{2}$ is a linear trend component, $S_{t}$ is a additive seasonal factor, $\varepsilon_{t}$ is the random error component

Let the length of the season be L periods. The seasonal factors are defined so that the sum of seasonal factors to the length is zero, i.e.

$$
\sum_{1 \leq t \leq L} S_{t}=0
$$

If the trend component $b_{2}$ deemed unnecessary then it can be deleted from the model. The forecasting equations used in the model along with the initial values to be used for the parameters. Let the current deseasonalized level of the process at the end of period $\mathrm{T}$ be denoted by $R_{t}, A_{t}$ the end of a time period $\mathrm{t}$, $\bar{R}_{t}$ be the estimate of the deseasonalized level, $G_{t}$ be the estimate of the trend, $\mathrm{S}_{t}$ be the estimate of seasonal component (seasonal index).

\subsubsection{Procedure for Updating the Estimates of Model Parameters}

Overall smoothing

$$
\bar{R}_{t}=\alpha\left(y_{t}-\bar{S}_{t-L}\right)+(1-\alpha) \times\left(\bar{R}_{t-1}+\bar{G}_{t-1}\right)
$$

where $0<\alpha<1$ is a smoothing constant.

Dividing $y_{t}$ by $\bar{S}_{t-L}$, which is the seasonal factor for period T computed one season (L periods) ago, deseasonalizes the data so that only the trend component and the prior value of the permanent component enter into the updating process for $\bar{R}_{t}$.

Smoothing of the trend factor

$$
\bar{G}_{t}=\beta \times\left(\bar{S}_{t}-\bar{S}_{t-1}\right)+(1-\beta) \times \bar{G}_{t-1}
$$

where, $0<\beta<1$ is a second smoothing constant. The estimate of the trend component is simply the smoothed difference between two successive estimates of the deseasonalized level.

Smoothing of the seasonal index

$$
\bar{S}_{t}=\gamma \times\left(y_{t}-\bar{S}_{t}\right)+(1-\gamma) \times \bar{S}_{t-L}
$$

where $0<\gamma<1$ is the third smoothing constant. The estimate of the seasonal component is a combination of the most recently observed seasonal factor given by the demand $y_{t}$ divided by the deseasonalized series level estimate $R_{t}$ and the previous best seasonal factor estimate for this time period. Since seasonal 
factors represent deviations above and below the average, the average of any $\mathrm{L}$ consecutive seasonal factors should always be 1 . Thus, after estimating $S_{t}$, it is good practice to re normalize the $\mathrm{L}$ most recent seasonal factors such that

$$
\sum_{i=t-q-1}^{t} S_{i}=q
$$

\section{Value of forecast}

The forecast for the next period is given by:

$$
y_{t}=\bar{R}_{t-1}+\bar{G}_{t-1}+\bar{S}_{t-L}
$$

So the best estimate of the seasonal factor for this time period in the season is used, which was last updated L periods ago.

All analyses are done using R studio (version 3.5.1), Statistical Package for Social Sciences (24), Excel (2016) and Tableau.

\section{Results and Discussion}

\subsection{Descriptive Studies}

In this section, different graphs and frequency distributions are used to examine the scenario and pattern of road traffic accidents with its fatalities.

\subsubsection{Trend of Road Accidents, Injuries \& Deaths (1971-2015)}

From Figure 1 it is observed that the general trends of number of accidents, injuries and fatalities are increasing with some fluctuations from 1971 to 2007. Number of accidents has increased by nearly 4 times from 1140 in 1971 to 4427 in 2007. The highest number of accidents reported is 5448 in the year 1997. The number of road accidents has been declined slowly from 2007 to 2015. Number of deaths has increased by nearly 20 times from 187 in 1971 to 3765 in 2008 . There is a slow decreasing trend in number of deaths after 2008. The highest number of deaths reported is 3765 in the year 2008. It also showed that number of injuries in 1997 is 5076 and the line decreases after 2008. It is also noticed that the line of the number of accident is always above that of the number of deaths from 1971 to 2011 and it coincides with other from 2012 which implies that the ratio of number of deaths to number of accident is increased in recent years.

\subsubsection{Rate of Registered Vehicles}

Figure 2 reveals that though the rate of register vehicles per 10,000 people is increased throughout the period but a sharp increment is exhibited after 2009.

\subsubsection{Mapping of Average Number of Road Accidents (2013-2017) in Bangladesh}

Figure 3 shows the average road accident in Bangladesh in different districts. From the map it is clear that in coastal and hill areas are less likely to have road accident compare to developed areas. The major road accidents are occurred in the divisional cities and its surroundings. 


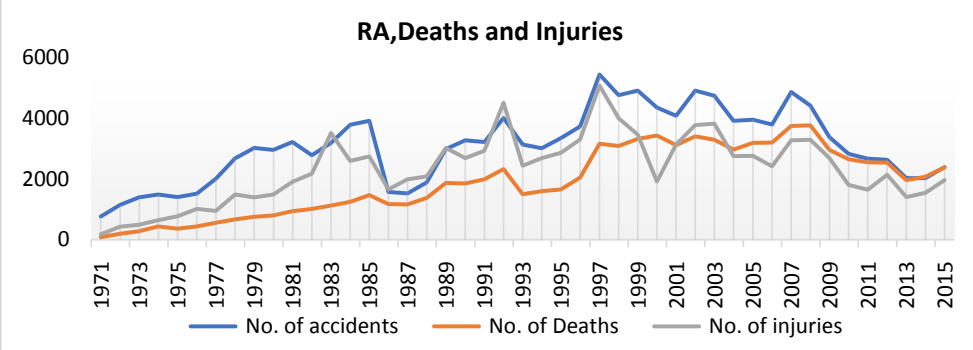

Figure 1. Line graph of road accidents, injuries \& deaths (1971-2015).

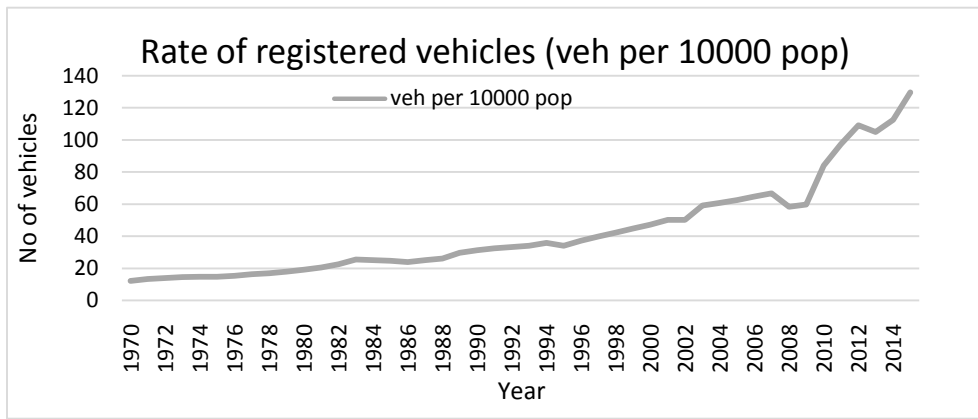

Figure 2. Rate of registered vehicle in Bangladesh per ten thousand populations.

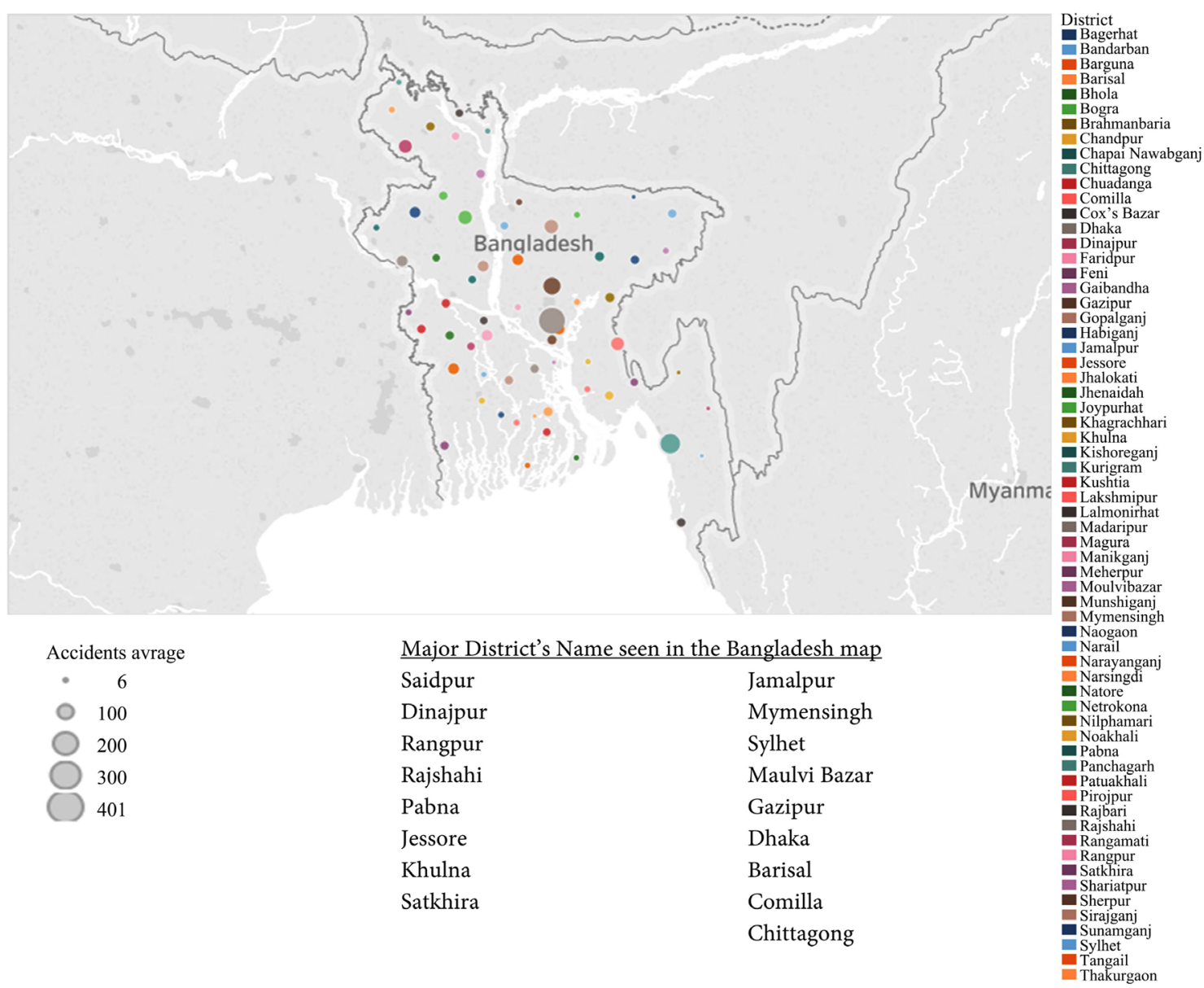

Figure 3. Mapping of average number of road accidents in Bangladesh. 


\subsubsection{Percentage of Accidents and Deaths in Different Divisions}

Figure 4 and Figure 5 show the percentage of accidents and deaths in different division in Bangladesh.

From Figure 4 it seems that around 34\% of the accidents occurred in Dhaka, $24 \%$ in Rajshahi, $17 \%$ in Chittagong and Khulna, Mymenshing, Sylhet, Barisal has $11 \%, 6 \%, 4 \%, 4 \%$ road accidents respectively.

Figure 5 shows that majority of deaths due to road accident occurred in Dhaka (32\%), Rajshahi (25\%), Chittagong (19\%) and Khulna Division (11\%), since the major high ways in the country lie among these divisions.

\subsubsection{Causalities of Road Accident in Different Age}

Table 1 represents that through road accident the maximum number of injuries is occurred between ages 21 and 30 while the maximum number of deaths is occurred between ages 11 and 30 .

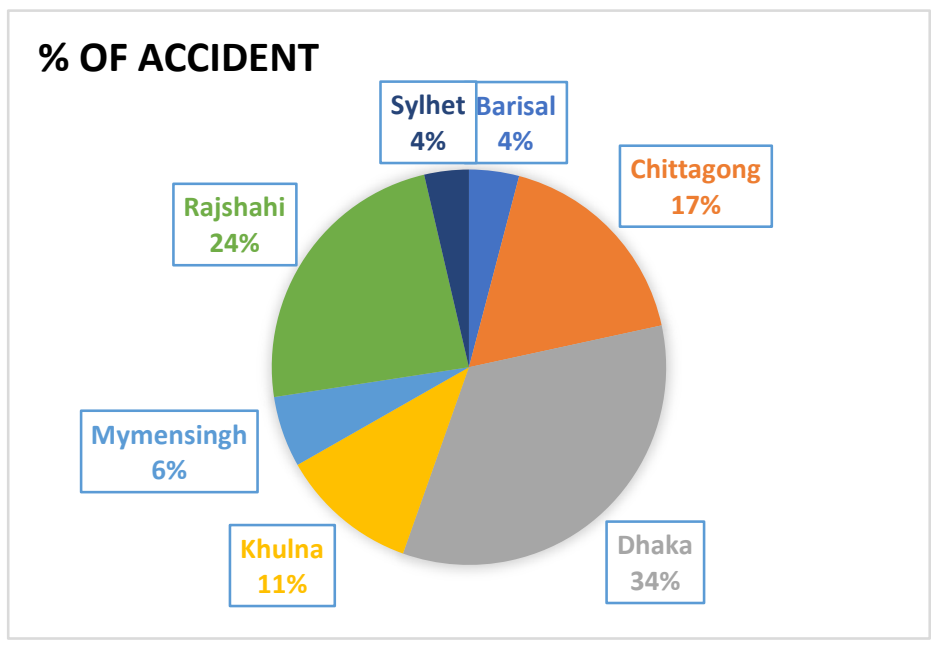

Figure 4. Percentage of accidents in different divisions in 2017.

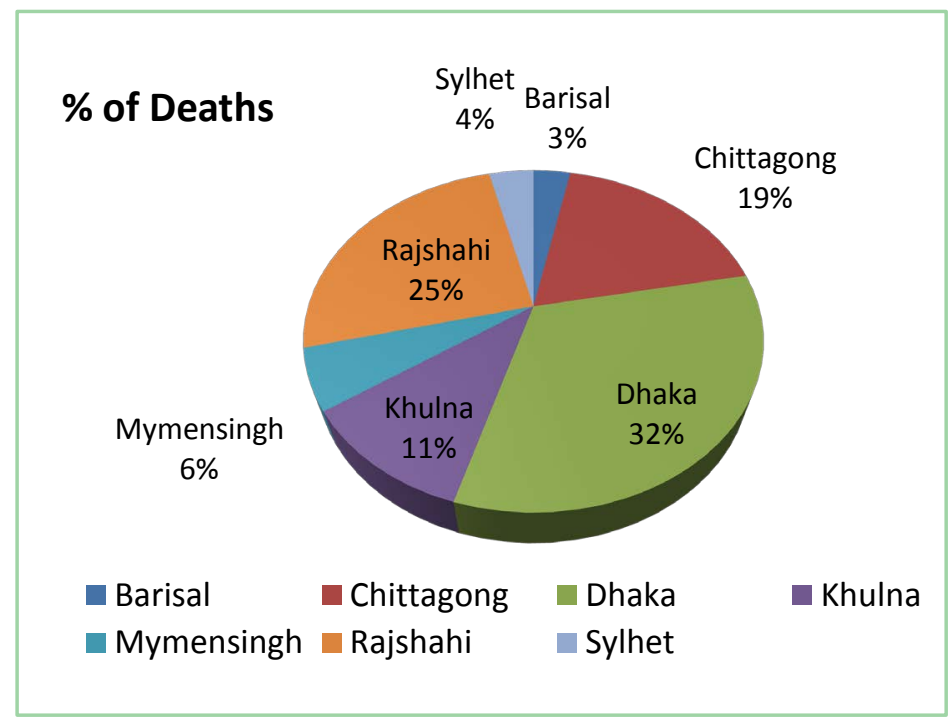

Figure 5. Percentage of deaths in different division in 2017. 
Table 1. Fatality distribution by age in 2017.

\begin{tabular}{ccccc}
\hline & \multicolumn{4}{c}{ Causalities of road accidents in 2017 } \\
\cline { 2 - 5 } Age interval & \multicolumn{3}{c}{ Injuries } & Deaths \\
\cline { 2 - 5 } & Number & \% of injuries & Number & \% of deaths \\
\hline 0 to 10 & 237 & 3 & 452 & 8 \\
11 to 20 & 870 & 11 & 1863 & 33 \\
21 to 30 & 3638 & 46 & 1411 & 25 \\
31 to 40 & 1344 & 17 & 395 & 7 \\
41 to 50 & 1107 & 14 & 452 & 8 \\
51 to 60 & 474 & 6 & 903 & 3 \\
61 to 70 & 238 & 3 & 169 & 160 \\
Total & 7908 & 100 & 5645 & \\
\hline
\end{tabular}

\subsubsection{Accidents by Different Clash Type}

From Figure 6 we notice that, accidents due to run over by vehicles is the highest in number. Head to head collision is the $2^{\text {nd }}$ reason which causes most of the accidents. The causes like, falling into the ditch, rolling over and others also cause accident.

\subsubsection{Death Causes by Different Clash Type}

In Figure 7 we can clearly see that, running over by vehicles is the main reason of accidental deaths. The $2^{\text {nd }}$ reason which causes death is head to head collision. Falling into the ditch and other reasons also causes death which is very miserable.

\subsubsection{Accidents Occurred by Different Vehicles}

From Figure 8 it is observed that all types of bus, track and motor cycle are responsible for the maximum number of accidents while covered van showed the least.

\subsection{Seasonal Variation}

The additive seasonal model is appropriate for a time series in which the amplitude of the seasonal pattern is independent of the average level of the series, i.e. a time series displaying additive seasonality.

\subsubsection{Observing Actual Time Plot of the Road Accident}

Represented in the below Figure 9 is the time plot of all the variables used in this analysis. A critical look at the plot shows that the series exhibited trend and seasonal effect. Since the plots cannot provide sufficient evidence to render the series not stationary, it is essential to use standard tests of stationarity.

Augmented Dickey Fuller (ADF) and Philip Perron tests are conducted to test the stationarity of the time series data. The absolute values of test statistics of ADF (3.5736) and Philip Perron (6.9755) are greater than the critical values 3.51 
and 6.70 respectively at $1 \%$ level of significance. Hence both tests are highly significant lead to the rejection of the null hypothesis indicating that there is no unit root. This implies that the data is stationary.

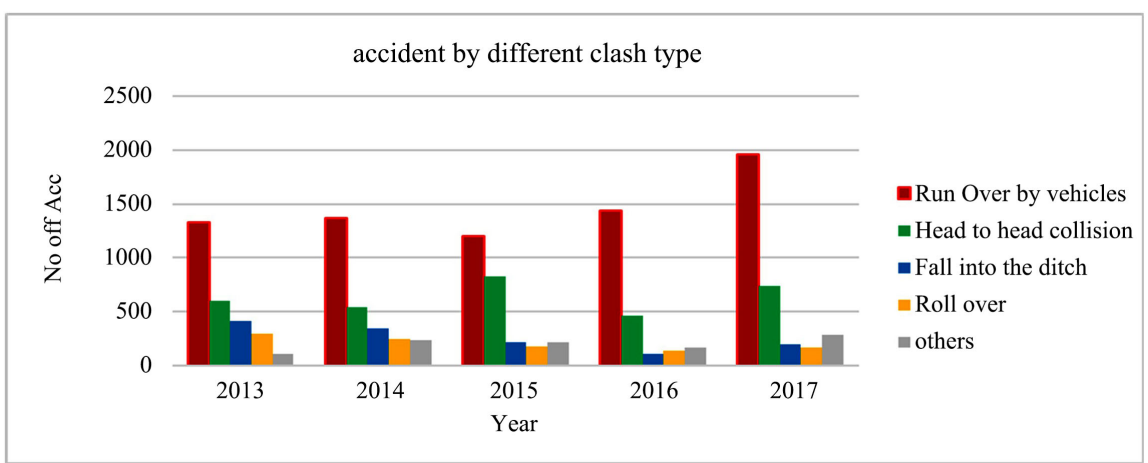

Figure 6. Accident by different clash type in last five years.

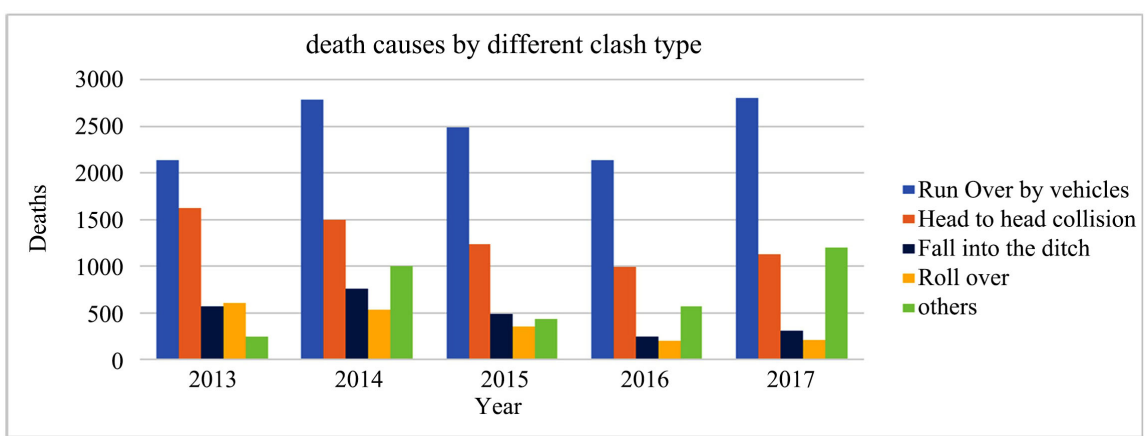

Figure 7. Different clash type (deaths).

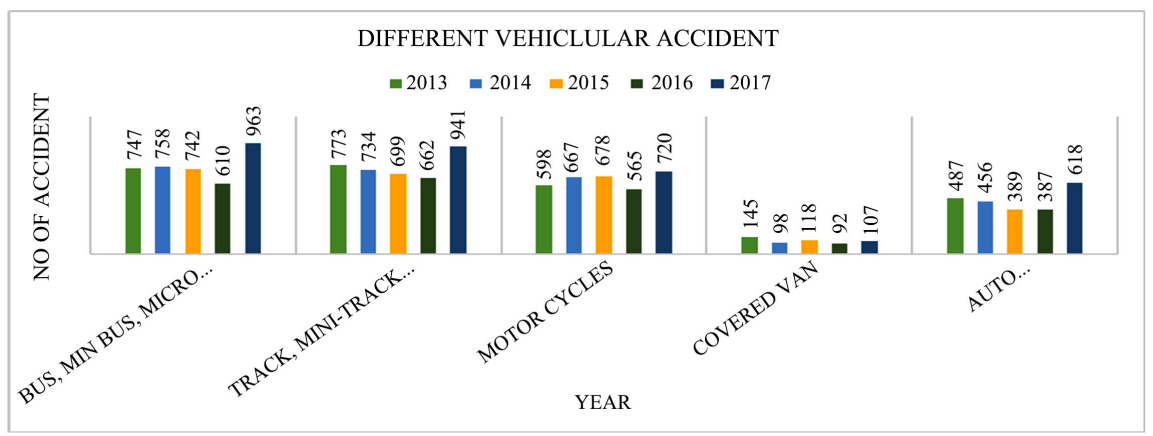

Figure 8. Accidents by different vehicle.

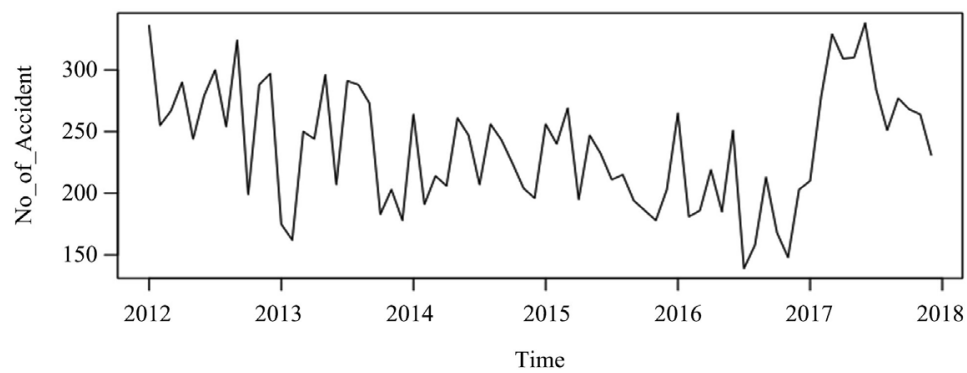

Figure 9. Time plot monthly reported road accident data in Bangladesh. 


\subsubsection{Decomposition of Road Accidents}

The accidents are decomposed using additive time series model which will show different component of this time series data.

Figure 10 shows the observed series, the smoothed trend line, the seasonal pattern and the random part of the series. The seasonal components in Table 2 show that the severity of occurring road accident is higher during the month of May, June and September since the major religious festivals ("Eid-Ul-Fitre" and "Eid-Ul-Azha" are Muslims' main festivals and "Durga puza" is the biggest festival of Hidu community) are usually occurred in these months. So it showed that there is slight seasonality of road accidents data in the past six years.

\subsection{Forecasting}

Now since the time series data has a little seasonality so we need to deseasonalize the data and perform log transformation and perform Holt-Winters filtering which showed the observed and fitted (log transformed) data shown in Figure 11 .

The smoothing model parameters are estimated using Equations (3), (4) and (5) and given in Table 2.

Table 2 shows that MSE (Mean square error) averagely, our model predictions are off by approximately 38. MASE (Mean absolute scaled error) also shows that it arises from a better forecast than the average naive forecast. ACF1 proposed that the correlation coefficient with the first lag is 0.134 .

Now we perform point forecasting up to 2020 using Holt-Winters exponential method with 95\% confidence interval and given in Table 3 .

Forecasting of road traffic accident eliminating seasonal impact for the next three consecutive years (2018-2020) is performed using Holt-Winters exponential technique and shown in Figure 12.

Table 2. Estimated smoothing parameters with error measures.

\begin{tabular}{cccc}
\hline \multicolumn{2}{c}{ Estimate of smoothing parameters } & \multicolumn{2}{c}{ Error measures } \\
\hline alpha & 0.2268784 & MAE & 37.87553 \\
beta & 0.0223799 & MASE & 0.72374 \\
gamma & 0.8333779 & ACF1 & 0.13436 \\
\hline
\end{tabular}

Table 3. Forecasting.

\begin{tabular}{cccc}
\hline \multirow{2}{*}{ Time } & Point Forecast & \multicolumn{2}{c}{$95 \%$ Confidence Interval } \\
\cline { 3 - 4 } & & Lower Limit & Upper Limit \\
\hline Jan 2018 & 302.1549 & 204.6712 & 399.6387 \\
Feb 2018 & 348.7169 & 248.6451 & 448.7888 \\
Mar 2018 & 330.1294 & 227.4244 & 432.8344 \\
\hline
\end{tabular}




\section{Continued}

\begin{tabular}{|c|c|c|c|}
\hline Apr 2018 & 316.0263 & 210.6443 & 421.4083 \\
\hline May 2018 & 277.5912 & 169.4893 & 385.6931 \\
\hline Jun 2018 & 305.0139 & 194.1501 & 415.8777 \\
\hline Jul 2018 & 258.1358 & 144.4691 & 371.8025 \\
\hline Aug 2018 & 232.4485 & 115.9386 & 348.9584 \\
\hline Sep 2018 & 250.9356 & 131.5432 & 370.3280 \\
\hline Oct 2018 & 293.7659 & 171.4523 & 416.0794 \\
\hline Nov 2018 & 273.8570 & 148.5844 & 399.1295 \\
\hline Dec 2018 & 256.1492 & 127.8805 & 384.4179 \\
\hline Jan 2019 & 302.4835 & 145.2912 & 459.6759 \\
\hline Feb 2019 & 349.0455 & 189.2812 & 508.8098 \\
\hline Mar 2019 & 330.4580 & 168.0747 & 492.8413 \\
\hline Apr 2019 & 316.3549 & 151.3063 & 481.4035 \\
\hline May 2019 & 277.9198 & 110.1603 & 445.6792 \\
\hline Jun 2019 & 305.3425 & 134.8273 & 475.8576 \\
\hline Jul 2019 & 258.4644 & 85.1495 & 431.7793 \\
\hline Aug 2019 & 232.7771 & 56.6190 & 408.9352 \\
\hline Sep 2019 & 251.2642 & 72.2203 & 430.3081 \\
\hline Oct 2019 & 294.0945 & 112.1227 & 476.0662 \\
\hline Nov 2019 & 274.1856 & 89.2447 & 459.1265 \\
\hline Dec 2019 & 256.4778 & 68.5270 & 444.4285 \\
\hline Jan 2020 & 302.8121 & 91.3960 & 514.2282 \\
\hline Feb 2020 & 349.3741 & 135.1629 & 563.5853 \\
\hline Mar 2020 & 330.7866 & 113.7371 & 547.8360 \\
\hline Apr 2020 & 316.6835 & 96.7531 & 536.6139 \\
\hline May 2020 & 278.2484 & 55.3949 & 501.1019 \\
\hline Jun 2020 & 305.6711 & 79.8529 & 531.4892 \\
\hline Jul 2020 & 258.7930 & 29.9692 & 487.6168 \\
\hline Aug 2020 & 233.1057 & 19.2357 & 464.9757 \\
\hline Sep 2020 & 251.5928 & 16.6367 & 486.5489 \\
\hline Oct 2020 & 294.4231 & 56.3415 & 532.5047 \\
\hline Nov 2020 & 274.5142 & 33.2681 & 515.7602 \\
\hline Dec 2020 & 256.8064 & 12.3575 & 501.2553 \\
\hline
\end{tabular}




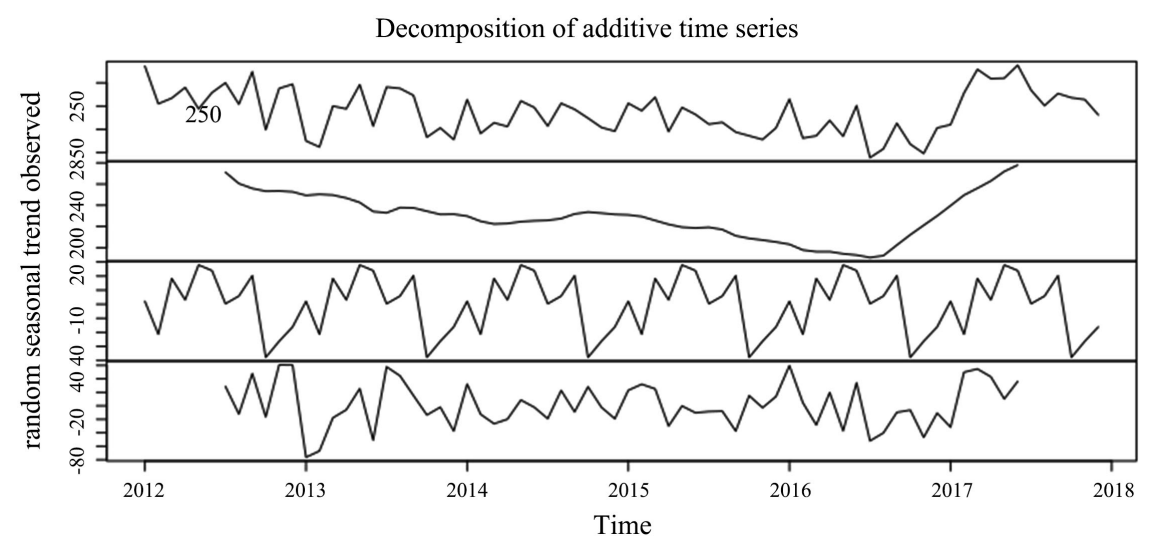

Figure 10. Different component of accidents throughout the year.

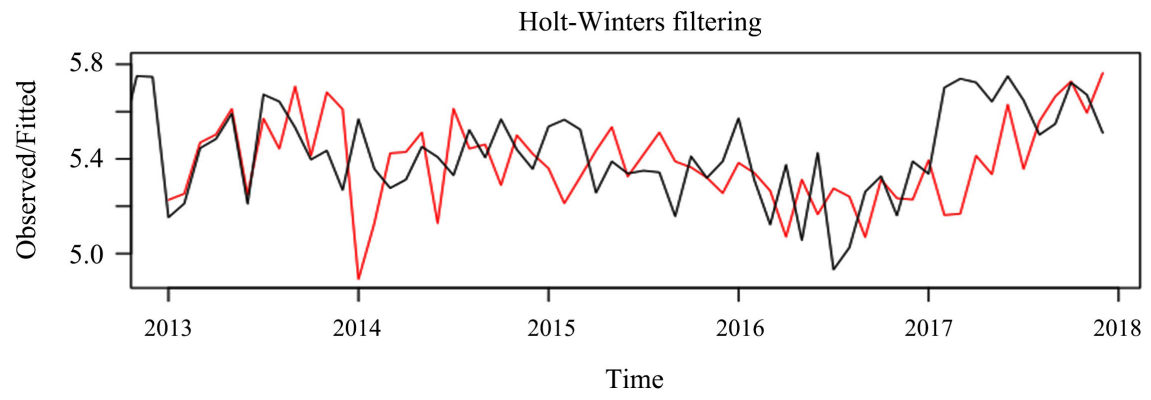

Figure 11. Holt Winter filtering.

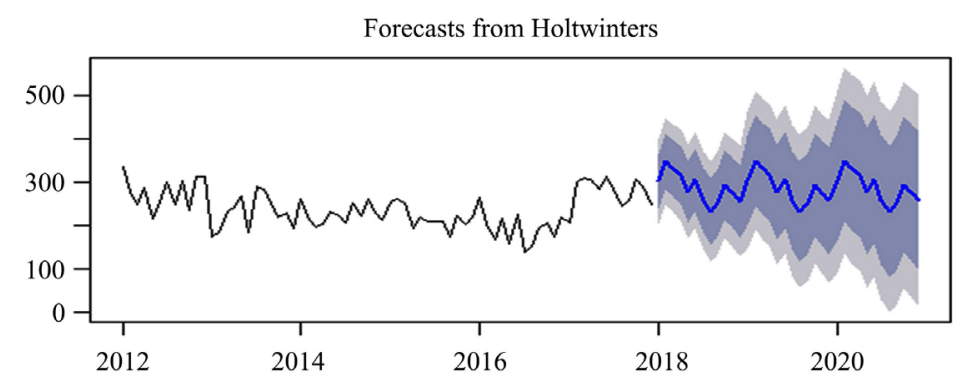

Figure 12. Forecasting of road traffic accidents from 2018 to 2020 in Bangladesh.

\section{Conclusions \& Recommendations}

\subsection{Conclusions}

This study has a great practical significance and it reflects the road accident situations. It also reflects whether there are any seasonal variations of the road accident and forecasts the road traffic accidents for the future. In the descriptive study we discussed the trend of road accident and its causalities, accident rate, vehicle rate show a clear picture of different infected district by road accident. We also elaborated the age of the affected people, type of accidents and different clash.

The general trends of road traffic accident (RTA), deaths and injuries reveal that the number of RTA, deaths and injuries increased gradually with little fluctuations form 1971 to 2007 and after 2007 there is a slow decreasing trend. Al- 
though the number of RTA and deaths observed decreasing trend in recent years, the ratio of number of deaths to number of accident increased significantly. The rate of register vehicles per 10,000 people increased moderately throughout the period but a sharp increment is exhibited from 2009. Highest percentage of RTA (34\%) and deaths is due to RTA (32\%) in Dhaka division while the lowest percentage of RTA (4\%) in Barisal and Sylhet divisions and deaths is due to RTA (3\%) in Barisal division. It is discovered that the maximum number of injuries occurred between ages 21 and 30 while the maximum number of deaths occurred between ages 11 and 30. Most of the RTA and deaths due to RTA are caused by run over by vehicles and head to head collision. The severity of occurring road accident is higher during the month of May, June and September since the major religious festivals ("Eid-Ul-Fitre" and "Eid-Ul-Azha" are Muslims' main festivals and "Durga puza" is the biggest festival of Hidu community) usually occurred in these months because of increasing movement.

The time plot shows that the graph maintains a decreasing movement from 2012 to 2015 but increases from 2015 to 2017. Holt-Winters smoothing parameters are estimated using an additive time series model with some error measurements after filtering. We performed forecasting of RTA eliminating seasonal impact for the next three consecutive years (2018-2020) with 95\% confidence interval using Holt-Winters exponential technique.

\subsection{Recommendations}

Based on the summary of the findings enumerated above on the number of road accidents, the number of cases will be reduced to the beeriest minimum by the government if the following recommendations are considered.

- Creating awareness about road safety: The government will have to increase efforts to promote awareness among stakeholders about the road safety issues and their social economic implications.

- Providing legal, institutional and financial environment for road safety: Many government organizations as well as various private agencies, share the responsibility of the various safety information data base. Detailed analysis of road accidents is essential if the causes of the accident are to be fully understood.

- The government should modernize data recording system of road traffic accidents in detailed and accessibility of all data.

- Activate the comprehensive observation: Verify vehicles fitness, drivers' license regularly. Traffic rules should be implemented too strictly to violate.

- Planned road connections and management: Existing roads should be broadened and one-way movement should be introduced. Pavements and roads must be kept occupation free.

\section{Acknowledgements}

We would like to express our gratitude and thanks to the Bangladesh Police, 
BRTA and NISHCA to provide us authentic data. We also take the opportunity to thanks of all our colleagues and staffs to extend their effective co-operations.

\section{Conflicts of Interest}

The authors declare no conflicts of interest regarding the publication of this paper.

\section{References}

[1] World Health Organization (WHO) (2015) Global Status Reports on Road Safety 2015. World Health Organization, Geneva, Switzerland.

http://www.who.int/violence_injury_prevention/road_safety_status/2015/en

[2] Paul, S. (2007) An Estimation of Socio-Economic Costs of Road Traffic Accidents in Bangladesh. Accident Research Institute (ARI), BUET, Dhaka, Bangladesh.

[3] Bangladesh Road Transport Authority (BRTA) (2017) 2017-Informal Publication.

[4] Prothom Alo (2018) Sharake Pachish Hajar Manusher Mertu. https://www.prothomalo.com/bangladesh/article/1546891/সড়ক -২৫-হাজ র-মা নুखরমৃত্যু

[5] Nirapad Sharak Cai (NISHCA) (2017) A Non-Government Organization Works with Road Traffic Accident in Bangladesh, Yearly Report.

[6] Banik, B.K., Chowdhury, M.A.I., Hossain, E. and Mojumdar, B. (2011) Road Accident and Safety Study in Sylhet Region of Bangladesh. Journal of Engineering Science and Technology, 6, 493-505.

[7] Ahsan, H.M., Raihan, M.A. and Rahman, M. (2011) A Study on Car Involvement in Road Traffic Accidents in Bangladesh. 4th Annual Paper Meet and 1st Civil Engineering Congress, Dhaka, Bangladesh 22-24 December 2011, 191-199. https://www.iebconferences.info

[8] Sonia, R. (2012) Development of an Accident Prediction Model for Intersections of Dhaka City, Bangladesh. International Journal of Computer Applications, 47, 10-16. https://doi.org/10.5120/7271-0389

[9] Ahmed, I. and Ahmed, B. (2013) Urban Road Accidents in Dhaka, Bangladesh. 16th International Conference on Road Safety on Four Continents, Beijing, 15-17 May 2013, 1-9.

[10] Mamun, M.M.H., Miah, M.M. and Islam, M.I. (2015) Present Condition of Road Traffic Accident: A Case Study of Rajshahi City, Bangladesh. International Journal of Computer Applications, 111, 36-41. https://doi.org/10.5120/19554-1279

[11] Favour, O.I., Joshua, A.F. and Ismail, S.O. (2016) Statistical Analysis of Pattern on Monthly Reported Road Accidents in Nigeria. Science Journal of Applied Mathematics and Statistics, 4, 119-128. https://doi.org/10.11648/j.sjams.20160404.11

[12] Baset, M.K.U., Rahman, A., Alonge, O., Agrawal, P., Wadhwaniya, S. and Rahman, F. (2017) Pattern of Road Traffic Injuries in Rural Bangladesh: Burden Estimates and Risk Factors. International Journal of Environmental Research and Public Health, 14, 1-13. https://doi.org/10.3390/ijerph14111354

[13] Nofel, F.H. and Sayeed, A.A.W. (1997) Seasonal Variation and Weather Effects on Road Traffic Accidents in Riyadh City. Public Health-Science Direct, 111, 51-55. https://doi.org/10.1038/sj.ph.1900297

[14] Ferdus, N., Matin, M. and Rana, M.M. (2018) Road Accidents and Safety Study of Rajshahi City in Bangladesh. Proceedings of the 4th International Conference on 
Civil Engineering for Sustainable Development (ICCESD 2018), Khulna, 9-11 February 2018.

[15] Holt, C.C. (1957) Forecasting Seasonal and Trends by Exponentially Weighted Moving Averages. Carnegie Institute of Technology, Pittsburgh PA. 